12. Стражникова Т.И. Проблемы интеграции дисциплин в региональной системе музыкального образования // Теория и практика общественного развития. 2012. № 12. С. 246-248.

13. Туравец Н.Р. Интеграция и дифференциация в системе профессионального музыкального образования // Многоуровневая система профессионального художественного образования: проблемы интеграции и дифференциации: сб. материалов регион. науч.практ. конф. Краснодар: КГУКИ, 2002. С. 3-19.

14. Шишлянникова Н.П. Интегрированный подход к профессиональной подготовке будущего учителя музыки // Вестник Томского государственного педагогического университета. 2012. № 11 (126). C. $38-41$.

15. Иофис Б.Р. М.И. Ройтерштейн: научная деятельность и авторская модель музыкально-теоретической подготовки учителя музыки // Вестник кафед- ры ЮНЕСКО Музыкальное искусство и образование. 2015. № 4 (12). С. 80-91.

16. Основы теоретического музыкознания: учеб. пособие для вузов по специальности 030700 - Музыкальное образование / А.И. Волков и др.; под ред. М.И. Ройтерштейна. М.: Academia, 2003. 271 с.

17. Ройтерштейн М.И. Введение в анализ гармонии: учеб. пособие. М.: Изд-во МГПИ им. В.И. Ленина, 1984. 87 с.

18. Ройтерштейн М.И. Полифония: учеб. пособие для музык. фак. педвузов. М.: Academia, 2002. 190 с.

19. Ройтерштейн М.И. Музыкальный язык: учеб. пособие по курсу музыкального анализа для музыкально-педагогического факультета педагогического вуза. М.: Изд-во МГПИ им. В.И. Ленина, 1973. 135 с.

20. Ройтерштейн М.И. Основы музыкального анализа: учеб. для студ. педвузов по специальности «Музыкальное образование». М.: Владос, 2001. 111 с.

\title{
INTEGRATIVE LINKS \\ IN MUSICAL-THEORETICAL AND MUSICAL-HISTORICAL CYCLES TEACHING
}

(C) 2019

Fedotova Tatiana Yurievna, postgraduate student of Musical Education Department; musical-theoretical subjects teacher, head of Musical Department

Samara State University of Social Sciences and Education (Samara, Russian Federation);

Samara Social-Pedagogical College (Samara, Russian Federation)

Nemirovskaya Iya Dmitrievna, doctor of philological sciences, professor of Musical Education Department

Samara State University of Social Sciences and Education (Samara, Russian Federation)

Abstract. This paper deals with actual questions of modernization of musical pedagogical middle level teaching. Specific thinking features of contemporary students are marked, and problems of innovative development of information society are described. Difficulties of secondary professional musical education are shown. System thinking and scientific knowledge integration are pointed out as a basis of new ideological settings formation. Scientific researches in musical pedagogy about integrative links are analyzed. A use of integrative links in teaching musicaltheoretical and musical-historical areas is marked as a necessary factor of solid and systematic music language image development. A language of music, as a complex of musical means of expression is named as an integrity factor. A system analysis of every element of music language aimed to discover their inner correlation and semantic role is named as a necessary clause, allowing to form a solid image of musical language and musical art in general. The authors justify a necessity of optimization and intensification of musical-theoretical schooling on the basis of integrative links inside the subjects of musical-theoretical and musical-historical cycles.

Keywords: globalization; information society; study process transition; clip mentality; system thinking; scientific knowledge integration; optimization of musical-theoretical schooling; subjects of musical-theoretical and musicalhistorical cycles; music language; integrative links; system analysis.

$* * *$

\section{ФОРМИРОВАНИЕ ПЕДАГОГИЧЕСКИХ КОМПЕТЕНЦИЙ У ИНОСТРАННЫХ СТУДЕНТОВ-ФИЛОЛОГОВ В КУРСЕ «ПРОФЕССИОГРАММА ПРЕПОДАВАТЕЛЯ РУССКОГО ЯЗЫКА КАК ИНОСТРАННОГО} (C) 2019

\author{
Филиппова Ольга Викторовна, доктор педагогических наук, доцент, \\ заведующий кафедрой русского языка как иностранного \\ Национальный исследовательский Мордовский государственный университет им. Н.П. Огарёва \\ (2. Саранск, Российская Федераџия)
}

Аннотация. В статье раскрывается роль учебной дисциплины вариативной части учебного плана по направлению подготовки 45.03.01 Филология (профиль «Преподавание русского языка как иностранного») «Профессиограмма преподавателя русского языка как иностранного» в формировании профессиональных компетенций бакалавра-филолога. Спрос на российское филологическое образование у иностранных абитуриентов во многом вызван желанием в дальнейшем заниматься преподавательской деятельностью. Федеральный государственный образовательный стандарт высшего образования по направлению 45.03 .01 Фило- 
логия предполагает формирование ряда педагогических компетенций, важных для будущего преподавателярусиста. Для приобретения необходимых компетенций, позволяющих в дальнейшем стать успешным специалистом, необходим комплекс знаний и умений, культуры и опыта, составляющий профессиограмму преподавателя русского языка как иностранного (РКИ). В статье рассматривается специфика учебной дисциплины «Профессиограмма преподавателя русского языка как иностранного», направленной на формирование педагогических компетенций, определено ее понятийное содержание, принципы и формы практической работы. В основе формирования педагогических компетенций лежит комплекс знаний о требованиях к профессиональной деятельности и личности педагога, педагогических способностях, слагаемых педагогического мастерства. Поскольку деятельность преподавателя РКИ является билингвально коммуникативной, особое значение в названном курсе имеет такое понятие, как коммуникативная личность преподавателя РКИ. Статья содержит примеры практико-ориентированных заданий, объединенных комплексной технологией риторизации, имеющих целью обогащение студентов тем конкретным опытом, который необходим для проектирования и рефлексии в будущей работе.

Ключевые слова: русский язык как иностранный; подготовка бакалавров-филологов; иностранные студенты; педагогические компетенции; профессиограмма преподавателя русского языка как иностранного; коммуникативная личность преподавателя русского языка как иностранного; принципы обучения педагогической коммуникации; риторизация; кейс-метод; риторическая задача.

Разработка учебных планов в соответствии с ФГОС ВО третьего поколения по разным направлениям подготовки, наполнение дисциплин практикоориентированным содержанием выступает на сегодняшний день одной из актуальных задач современной высшей школы. Переход на построение гибкой системы обучения необходимым профессиональным компетенциям с учётом принципов фундаментализма, ориентации на интересы развития личности и гуманизма в совокупности с учётом спроса рынка труда заставляет искать оптимальное сочетание содержания и форм подготовки будущих специалистов. Сказанное в полной мере имеет отношение к подготовке иностранных студентов бакалавриата по направлению 43.03.01 Филология.

В настоящее время наблюдается спрос на получение российского филологического образования со стороны иностранных студентов из азиатских и ряда африканских стран. Причины этого кроются как в привлекательности российского образования, популярности русского языка, в перспективах овладения им, так и связаны с развитием экономических и культурных связей между РФ и странами, откуда приезжают учиться студенты, а также желанием интегрироваться в российскую социокультурную среду и т.п.

Среди иностранных студентов-филологов, обучающихся в 2017-2018 гг. в Национальном исследовательском Мордовском государственном университете имени Н.П. Огарёва, был проведён опрос. В опросе участвовали 46 человек из Туркменистана, Таджикистана, Судана, Узбекистана. На вопрос, с какой целью они изучают русскую филологию, 74\% ответили, что хотят стать учителями, преподавать русский язык, 10\% видят применение своих знаний в переводческой деятельности, 16\% не задумывались о конкретной специальности, но уверены, что знание русского языка поможет получить работу.

Подготовка филолога в отечественной системе филологического образования всегда была сопряжена и с подготовкой в сфере преподавания. Овладение в процессе филологической подготовки педагогическими компетенциями обеспечивает выпускнику уверенность на рынке труда. Таким образом, выбор научно-исследовательской и педагогической в качестве конкретных видов профессиональной деятельности, к которым готовится бакалавр по направле- нию 45.03.01 Филология, вполне логичен и закономерен.

Однако конкретное наполнение учебного плана дисциплинами, наиболее полно отвечающими современным требованиям подготовки будущего филолога-преподавателя, остаётся актуальной задачей. При разработке курсов, нацеленных на формирование профессиональных компетенций, важно заложить в них не только необходимое содержание, но и предусмотреть эффективные, культуросберегающие, инновационные формы его усвоения.

Цель статьи - рассмотреть обучающие и развивающие возможности содержания и форм реализации курса «Профессиограмма преподавателя русского языка как иностранного», направленного на формирование педагогических компетенций, в системе профессиональной подготовки студента-филолога в соответствии с ФГОС ВО.

Как известно, профессиограмма - это требования профессии к видам деятельности и к качествам личности специалиста, так сказать «обобщенная эталонная модель успешного специалиста» $[1$, с. 16]. Исчерпывающую обобщающую характеристику знаний, умений и трудовых действий педагога, преподавателя, воспитателя мы найдём в профстандарте «Педагог» [2]. Применительно к преподавателю иностранного языка набором характеристик представлена профессиограмма в работе С.А. Дерябина и Т.А. Дьяковой, где отчётливо видна академическая и прикладная составляющие. К первой относятся знания по преподаваемому языку и связанные с ними «понимание типологических отличий русского языка от родного языка учащихся», «понимание лингвокультурологических особенностей обучающихся», включая правила коммуникативного поведения; навыки научно-исследовательской деятельности. К прикладной - «владение методикой его преподавания», «информационная культура» [3, с. 143].

Однако следует различать профессиограмму преподавателя русского языка как иностранного (РКИ) как совокупность изложенных характеристик и «Профессиограмму преподавателя русского языка как иностранного» как учебную дисциплину. Если первая отражает владение педагогическими компетенциями применительно к области преподавания РКИ, то вторая - учебная дисциплина - призвана 
способствовать овладению этими компетенциями или отдельными их составляющими.

Под педагогическими компетенциями понимается комплекс знаний и умений, включающих знание предмета преподавания, психологии личности, дидактики, эффективных средств педагогического воздействия, умения воздействовать на учеников, мотивировать их к обучению и саморазвитию, владение способами подачи учебного материала, методами формирования надучебных и специальных умений по предмету и т.п.

В формулировках профессиональных компетенций в области педагогической деятельности, указанных в ФГОС по направлению 45.03.01 Филология они значатся как: «способность к проведению учебных занятий и внеклассной работы по языку и литературе в общеобразовательных и профессиональных образовательных организациях (ПК-5); умение готовить учебно-методические материалы для проведения занятий и внеклассных мероприятий на основе существующих методик (ПК-6); готовность к распространению и популяризации филологических знаний и воспитательной работе с обучающимися (ПК-7)» [4].

Очевидно, что такой комплекс знаний и умений формируется не одной дисциплиной. В профессиональную педагогическую подготовку филолога вносят свой вклад такие дисциплины, как «Основы психологии и педагогики», «Методика обучения РКИ» и др.

Цель же курса «Профессиограмма преподавателя русского языка как иностранного» заключается в осознании и развитии таких личностных качеств и способностей, которые наиболее востребованы в педагогической работе в целом и работе преподавателя РКИ в частности и которые наиболее успешно позволяют её осуществлять.

Исходя из этого, авторы-разработчики курса, в том числе и автор настоящей статьи, ставили перед собой задачу при отборе содержания вычленить профессионально значимые понятия, составляющие основу для изучения себя как профессиональной личности, и умения, обеспечивающие развитие педагогически релевантных способностей.

Содержательно-понятийную основу курса составляют знания о профессиональной роли педагога, что, на наш взгляд, для воспитания будущего педагога имеет большое значение. Важное место отводится особенностям педагогической деятельности, ряду основополагающих документов, регулирующих деятельность педагога в Российской Федерации [2; 4], требованиям к личности преподавателя РКИ, педагогическим способностям и основам педагогического мастерства, детально описанным в отечественной педагогической науке [5-7].

Деятельность преподавателя РКИ является билингвально коммуникативной, поэтому особое значение имеет в названном курсе такое понятие, как коммуникативная личность преподавателя РКИ (КЛ преподавателя РКИ), выступая стержнеобразующим понятием теоретического наполнения данного курса.

Поскольку «существование большого количества моделей языковой личности и коммуникативной личности и выбор их регулируется практикой» $[8$, c. 18], с учётом содержания курса следует выделить в КЛ преподавателя РКИ прежде всего такие свойства личности, которые помогают осуществлять педагогическую коммуникацию. То есть, методически целесообразным считаем рассматривать его не только с опорой на существующие модели ряда учёных $[9 ; 10]$, но и в аспекте требований к личности педагога, детально описанных в отечественной педагогике, а также характеристик личности человека будущего, составляющих предмет изучения и научных дискуссий в современной науке. Особое значение имеют, на наш взгляд, такие компетенции, которые способствуют универсализации и устойчивости коммуникативной личности, а именно «знание языков и культуры», «работа в команде», «творческое мышление», «саморегуляция», «управление изменениями» [11, c. 105].

В результате исследования создана уровневая модель КЛ через характеристику способностей/готовностей к педагогической коммуникации, а именно КЛ преподавателя РКИ отличают:

1) на ценностном уровне - готовность присвоить ценности педагогического дискурса;

2) на мотивационном уровне - готовность к педагогическому общению;

3) на прагматическом уровне - готовность использовать различные средства педагогического воздействия, способность отбирать продуктивные и адекватные для обучающихся технологии работы с языковым и текстовым материалом.

Таким образом, КЛ преподавателя РКИ как стержнеобразующее понятие курса отражает модель КЛ носителя языка во взаимосвязи со способностями и готовностями использовать язык в педагогически заданных целях. Это взаимосвязь обобщённо представлена в таблице 1.

Данное понятие аккумулирует принципы и подходы к формированию профессиональных компетенций будущего преподавателя РКИ, в частности профессиональной иноязычной компетенции. Суммируя принципы, выделяемые в дидактике и лингводидактике, выделим те, которые наиболее полно отвечают задачам курса «Профессиограмма преподавателя русского языка как иностранного» и которые находят воплощение в его реализации.

В числе принципов дидактики важное значение имеют принципы дидактики непрерывного профессионального образования: антропоцентризма, синергетики и интегративности, междисциплинарности, профессиональной ориентации, рассмотренные в монографии А.К. Крупченко и А.Н. Кузнецова [12]. В числе принципов лингводидактики наиболее оптимальными являются принципы, сформулированные М.А. Богатырёвой, синтезирующие по сути общедидактические принципы с учётом позиции когнитивизма в формировании профессиональной иноязычной компетенции [13]. Остановимся на тех, которые были выбраны как ведущие при формировании педагогических компетенций: практико-праксиологический, ценностно-аксиологический и личностно-профессиональный.

Проблемно-праксиологический принцип сообразуется с практико-ориентированным подходом к обучению иностранным языкам и предполагает овладение подходами к решению профессиональных задач «овладение системой технологий решения профессиональных задач» [13, с. 75]. 
Таблица 1 - Взаимосвязь уровней коммуникативной личности преподавателя РКИ с ФГОС ВО направления 45.03.01 Филология и профессиональным стандартом «Педагог»

\begin{tabular}{|c|c|c|c|}
\hline $\begin{array}{c}\text { Уровни } \\
\text { КЛ } \\
\text { препо- } \\
\text { давате- } \\
\text { ля РКИ }\end{array}$ & $\begin{array}{c}\text { Способности / } \\
\text { готовности }\end{array}$ & $\begin{array}{c}\text { Профессиональные } \\
\text { компетенции в области } \\
\text { педагогической деятель- } \\
\text { ности (ФГОС ВО } \\
\text { по направлению } \\
45.03 .01 \text { Филология) }\end{array}$ & Профессиональный стандарт «Педагог»* \\
\hline $\begin{array}{l}\text { Цен- } \\
\text { ност- } \\
\text { ный }\end{array}$ & $\begin{array}{l}\text { Присвоить ценности } \\
\text { педагогического дис- } \\
\text { курса, воплощать в ин- } \\
\text { дивидуальной форме } \\
\text { требования к профес- } \\
\text { сиональной роли педа- } \\
\text { гога, реализовывать } \\
\text { требования образова- } \\
\text { тельного стандарта по } \\
\text { РКИ }\end{array}$ & $\begin{array}{l}\text { Умение готовить учеб- } \\
\text { но-методические мате- } \\
\text { риалы для проведения } \\
\text { занятий и внеклассных } \\
\text { мероприятий на основе } \\
\text { существующих методик } \\
\text { (ПК-6) }\end{array}$ & $\begin{array}{l}\text { Общепедагогическая функция. } \\
\text { Обучение. } \\
\text { Трудовые действия } \\
\text { Планирование и проведение учебных занятий } \\
\text { Необходимые умения } \\
\text { Владеть формами и методами обучения, в том } \\
\text { чсле выходящчии за рамки учебных занятий } \\
\text { Необходимые знания } \\
\text { Преподаваемьй предмет в пределах требований } \\
\text { федеральных государственных образовательных }\end{array}$ \\
\hline $\begin{array}{l}\text { Моти- } \\
\text { ваци- } \\
\text { онный }\end{array}$ & $\begin{array}{l}\text { Вступать в конструк- } \\
\text { тивное взаимодействие } \\
\text { с обучающимися, осу- } \\
\text { ществлять содействие } \\
\text { в усвоении РКИ, раз- } \\
\text { вивать и воспитывать } \\
\text { средствами РКИ }\end{array}$ & $\begin{array}{l}\text { Готовность к распро- } \\
\text { странению и популяри- } \\
\text { зации филологических } \\
\text { знаний и воспитательной } \\
\text { работе с обучающимися } \\
\text { (ПК-7) }\end{array}$ & $\begin{array}{l}\text { стандартов и основной общеобразовательной } \\
\text { программыл } \\
\text { Воспитательная деятельность } \\
\text { Трудовые действия } \\
\text { Реализащия современньх, в том числе интерак- } \\
\text { тивных, форм и методов воспитательной ра- } \\
\text { боть, используя их как на занятии, так и во }\end{array}$ \\
\hline $\begin{array}{l}\text { Праг- } \\
\text { мати- } \\
\text { ческий }\end{array}$ & $\begin{array}{l}\text { Использовать разнооб- } \\
\text { разные вербальные и } \\
\text { невербальные формы } \\
\text { эффективного педаго- } \\
\text { гического воздействия } \\
\text { (взаимодействия) на } \\
\text { уроках РКИ и внеклас- } \\
\text { сных занятиях, проду- } \\
\text { цировать тексты раз- } \\
\text { ных жанров педагоги- } \\
\text { ческой речи с целью } \\
\text { решения актуальных } \\
\text { задач преподавания } \\
\text { РКИ }\end{array}$ & $\begin{array}{l}\text { Способность к проведе- } \\
\text { нию учебных занятий и } \\
\text { внеклассной работы по } \\
\text { языку и литературе в } \\
\text { общеобразовательных и } \\
\text { профессиональных обра- } \\
\text { зовательных организа- } \\
\text { циях (ПК-5) }\end{array}$ & 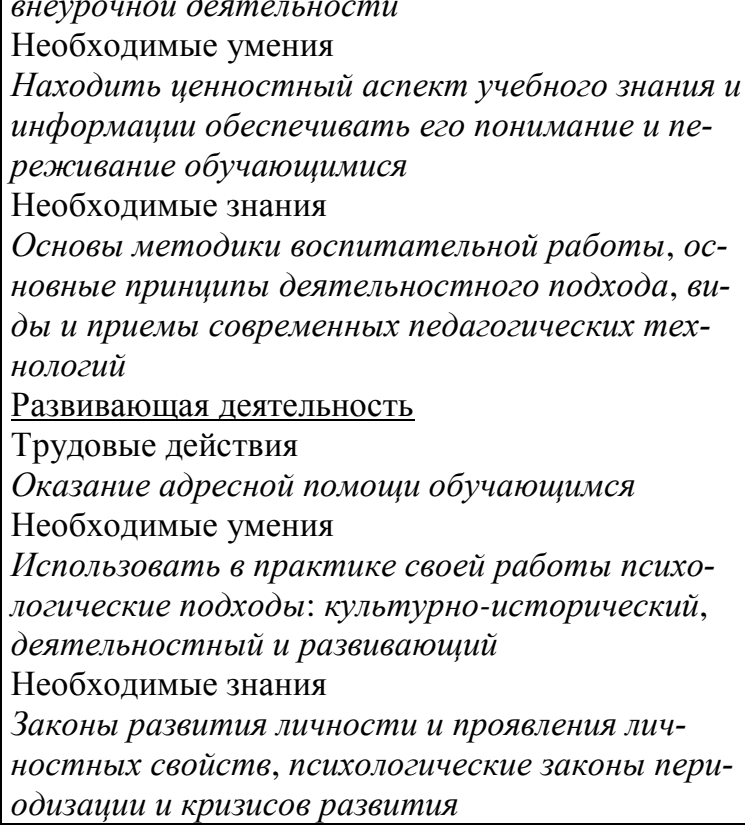 \\
\hline
\end{tabular}

Примечание. * В целях репрезентативности в таблице выборочно представлены характеристики трудовых действий, необходимых умений и знаний, иллюстрирующих содержательно-целевое назначение понятия «КЛ преподавателя РКИ» в курсе «Профессиограмма преподавателя русского языка как иностранного».

Следует выделить несколько подходов к реализации данного принципа.

Во-первых, курс содержит тесты, направленные на оценку уровня владения профессионально значимыми качествами личности и способностями.

Во-вторых, данный принцип выражается в обращении к примерам из реальной педагогической практики, иллюстрирующим деятельность, к которой готовится студент. Прежде чем творчески подходить к решению проблемы, необходимо представлять себе, как может выглядеть её решение. Это способствует повышению мотивации овладения будущим преподавателем РКИ арсеналом коммуникативных стратегий и тактик организации учебного общения, методов и приёмов лексической, грамматической и культурологической работы на уроках РКИ. Например:

«Просмотрите видеофрагмент урока РКИ и обратите внимание на коммуникативное поведение преподавателя, а именно:

1. Какими словами преподаватель настраивает учащихся на урок?

2. Как преподаватель мотивируют учащихся на активную речевую деятельность?

3. Какие средства использует преподаватель для того, чтобы облегчить учащимся усвоение новой лексики?

4. Как преподаватель реагирует на реплики учащихся? 
5. Что помогает преподавателю организовать общение на уроке? Какие фразы использует преподаватель для поощрения учащихся?

6. Соблюдает ли преподаватель требования к коммуникативному поведению на уроке? Какой стиль общения демонстрирует преподаватель?» и т.п.

В-третьих, методика преподавания курса включает активные формы и инновационные технологии обучения (проектную технологию, кейс-метод и др.).

Формирование педагогических компетенций с их помощью считаем не только эффективным, но и обязательным. Во-первых, благодаря этому создаётся, как сформулировал А.В. Вербицкий, «квазипрофессиональная деятельность, моделирующая в аудиторных условиях и на языке науки условия, содержание и динамику производства, отношения занятых в нем людей» [14, с. 47]. Во-вторых, будущий учитель русского языка сможет эффективно использовать инноватику в собственной педагогической практике, только если сам получил опыт формирования компетенций через них, смог оценить эффективность применяемых методов и приёмов, прочувствовать их творческий потенциал.

В курсе «Профессиограмма преподавателя русского языка как иностранного» предусмотрено погружение студента в атмосферу продуктивной коммуникативно-речевой деятельности, которая с учётом лингвометодической специфики возможна «на основе конструирования комплексной технологии, которая интегрирует элементы нескольких монотехнологий на основе приоритетной оригинальности авторской идеи» $[15$, с. 35$]$. В числе комплексной технологии целесообразно использовать риторизацию.

Риторизация обучения на первый план выдвигает осмысленную риторическую деятельность с предметным содержанием (выдвижение гипотезы, построение программы действий, алгоритмов, апробирование собственных гипотез, планов, проектов, проверка и оценка, рефлексия - осмысление и оценка собственного коммуникативно-познавательного опыта). Эта технология наиболее приближена к задачам коммуникативного обучения языку, формирования тех коммуникативных умений, которые составляют базовую компетенцию «в условиях быстро изменяющихся потребностей общества, непрерывного появления новых технологий» [16]. Что касается формирования педагогических компетенций в указанном курсе, то она обеспечивает «широкое использование коллективных форм работы, внимание к проблемным ситуациям и творческим видам занятий» $[17$, c. 166].

Риторизация включает риторические (коммуникативные / ситуационные / педагогические / методические) задачи - аналог «информационно-компетентностной задачи как структурной единицы кейстехнологии» $[18$, с. 80$]$ в обучении речевому общению. Поскольку практически любая педагогическая или методическая задача сопряжена с выбором вербальных и невербальных средств её решения, такая задача становится риторической. Следуя структуре кейс-метода, изложенной в работе И.Г. Липатниковой и С.В. Мечик [18], обозначим её составляющие. $\mathrm{B}$ основе такой задачи лежит моделирование профессионально направленной коммуникативной ситуации, что представляет сюжетную часть кейс-метода.
В качестве методической части выступает междисциплинарная связь между методикой обучения РКИ и профессиограммой преподавателя РКИ, а в качестве информационной та полезная информация, с опорой на которую студент решает риторическую задачу, создаёт тексты устных, письменных или электронных педагогических жанров, выбирает оптимальные коммуникативные стратегии и тактики и т.п. Такие задачи помогают студенту не только овладевать необходимой информацией, но и должным образом структурировать её, «понять суть поставленной проблемы, принять определенное решение и лингвистически его оформить» [19, с. 27].

Пример задачи, предлагаемой при изучении темы «Этапы профессионального становления. Педагогическое мастерство»:

«Как вы понимаете выражение «очеловечивание» знания»?

Проанализируйте лингвистическую сказку автора Феликса Кривина из книги «Несерьёзные Архимеды». Каким образом проявляет себя приём очеловечивания в данной сказке?

\section{Инфинитив}

Смотрит Инфинитив, как спрягаются глаголь, $и$ говорит:

- Эх вы, разве так надо спрягаться?

- А как? - спрашивают глаголы. - Ты покажи.

-Я б показал, - сокрушается Инфинитив, только у меня времени нет.

- Время мы найдём, - обешают глаголы. - Какое тебе: настоящее, промедшее или будущее?

- Давайте будущее, - говорит Инфинитив, чтобы хоть немного оттянуть время. - Да не забудьте про вспомогательный глагол. Спрягается Вспомогательный глагол - только окончания мелькают. А Инфинитив и буквой не помевелит.

Зачем ему спрягаться? Он - Инфинитив, у него нет времени [20, с. 16].

Охарактеризуйте Инфинитив как персонаж сказки. Какими чертами человеческого характера наделил его автор? Какое явление русской грамматики нашло отражение в этой сказке?

Что вы скажете об учителе, который использует такой приём в своей работе? О каких педагогических способностях это говорит?

Представьте, что вы ведёте урок РКИ, на котором изучаете с учениками формы русского глагола. Продумайте и сформулируйте возможные варианты использования данной сказки в процессе изучения».

Подобные задачи призваны способствовать обогащению студентов тем конкретным опытом, который необходим для проектирования и рефлексии в будущей работе.

Ценностно-аксиологический, связанный с эмоциональными потребностями личности, и профессионально-личностный принцип, объединяющий все указанные принципы, реализуются в данном курсе через обращение к личности преподавателя РКИ в аспекте ориентации на развитие коммуникативно значимых способностей, раскрытия путей становления профессионального мастерства педагога, развития в себе важных сторон коммуникативной личности.

Приведём пример задачи, подготавливающей студента к участию в круглом столе как интерактивной форме обучения. Цель этой и подобных форм 
обучения - помочь студенту осмыслить профессиональную роль педагога на ценностно-личностном уровне, усвоить коммуникативные формы, соответствующие той или иной роли, обогатить профессиональный тезаурус студентов, развивать навыки профессиональной коммуникации: «Подготовьтесь к участию в Круглом столе на тему «Что важнее для преподавателя РКИ: быть лидером, быть организатором или быть фасилитатором?»

Для подготовки вам необходимо:

1) Ознакомиться с указанными ниже статьями и материалами, пройдя по ссылке (указываются $U R L$ адреса).

2) Ответить на вопросы: Является ли преподаватель РКИ лидером? Что значит быть коммуникативным лидером? Лидерские качества и организаторские способности - это одно и то же или нет? Докажите свою точку зрения. Что общего между организаторскими способностями и умением выступать в роли фасилитатора? Что нужно развивать будущему преподавателю РКИ: лидерские качества, организаторские способности или способность быть фасилитатором? В чём может проявиться роль фасилитатора в работе преподавателя РКИ? Ответы подкрепите примерами.

3) Подготовить сообщение или эссе на одну из тем: «Преподаватель РКИ: пять лидерских качеств для успешной работы», «Какие лидерские качества помогут мне в работе преподавателя РКИ?», «В чём проявляются организаторские способности преподавателя РКИ?», «Как я представляю себе роль преподавателя-фасилитатора».

Таким образом, обучающие и развивающие возможности курса «Профессиограмма преподавателя русского языка как иностранного» как звена в педагогической подготовке филолога заключаются в том, чтобы через общие закономерные требования к коммуникативной личности педагога вывести студентов к осознанию способов преломления этих требований к конкретной коммуникативной деятельности преподавателя РКИ. Через комплекс традиционных форм и инновационных технологий обучения, формирующих педагогические компетенции, студент мотивируется на выбор педагогически оправданных решений в процессе обучения РКИ, поиск своего индивидуального стиля преподавательской деятельности.

\section{Список литературы:}

1. Маркова А.К. Психология профессионализма. М.: Изд-во «Международный гуманитарный фонд "Знание"», 1996. 312 с.

2. Профессиональный стандарт «Педагог» (педагогическая деятельность в сфере дошкольного, начального общего, основного общего, среднего общего образования) (воспитатель, учитель) // Минтруд России [Электронный ресурс]. - https://rosmintrud.ru/ docs/mintrud/orders/129.

3. Дерябина С.А., Дьякова Т.А. Профессиограмма преподавателя иностранного языка в условиях цифровизации образовательного пространства // Высшее образование в России. 2019. № 4. С. 142-149.

4. Федеральный государственный образовательный стандарт высшего образования по направлению подготовки 45.03.01 Филология (уровень бакалавриата): приказ Минобрнауки России от 07.08.2014
№ 947 // Портал Федеральных государственных стандартов высшего образования [Электронный ресурс]. - http://fgosvo.ru.

5. Кузьмина Н.В. Профессионализм личности преподавателя. М.: Высшая школа, 1990. 119 с.

6. Чернявская А.П. Педагогическая техника в работе учителя. М.: Педагогический поиск, 2001. 176 с.

7. Станкин М.И. Профессиональные способности педагога: Акмеология воспитания и обучения. М.: Московский психолого-социальный институт; Флинта, 1998.368 с

8. Арискина О.Л., Дрянгина Е.А. Языковая и коммуникативная личность: различные подходы к исследованию // Вестник Челябинского государственного университета. 2011. № 25 (240). Филология. Искусствоведение. Вып. 58. С. 15-18.

9. Карасик В.И. Языковой круг: личность, концепты, дискурс. Волгоград: Изд-во «Перемена», 2002. $477 \mathrm{c}$.

10. Конецкая В.П. Социология коммуникации. М.: Международный университет бизнеса и управления, 1997. 304 c.

11. Абрамова О.А. Профессии будущего: какие компетенции будут необходимы сотрудникам? // Международный журнал гуманитарных и естественных наук. 2017. Vol. 11. P. 102-105.

12. Крупченко А.К., Кузнецов А.Н. Генезис и принципы профессиональной лингводидактики: монография. М.: АПК и ППРО, 2011. 140 с.

13. Богатырёва М.А. Профессиональная языковая подготовка в высшей школе в контексте социообразовательных реформ: монография. М.: Изд-во «Флинта: Наука», 2015. 164 с.

14. Вербицкий А.А. Компетентностный подход и теория контекстного обучения. М.: Изд-во «ИЦ ПКПС», 2004. 84 c.

15. Зиновьева Т.И. Проблемы профессиональной подготовки педагога школы будущего // Начальное филологическое образование и подготовка учителя в контексте проблемы формирования у обучающихся навыков и компетенций XXI века: мат-лы междунар. науч.-практ. конф. преподавателей, аспирантов, студентов (28 февраля 2019 года) / сост. и отв. ред.: Т.И. Зиновьева. М.: Изд-во «Экон-Информ», 2019. С. 29-36.

16. Ладыжеснкая Т.А. Модернизация образования и риторика [Электронный ресурс] // Лаборатория риторики и диалога культур. - http://lab-ritor.ucoz.ru/ load/4-1-0-42.

17. Капитонова Т.И., Московкин Л.В., Щукин А.Н. Методы и технологии обучения русскому языку как иностранному / под ред. А.Н. Щукина. 2-е изд., стереотип. М.: Изд-во «Русский язык. Курсы», 2019. $312 \mathrm{c}$.

18. Липатникова И.Г., Мечик С.В. Кейс-технология как одно из средств подготовки будущих инженеров к анализу и оценке химико-технологического процесса // Педагогическое образование в России. 2018. № 4. С. 78-84.

19. Фёдорова Е.А., Нестерова Е.Н., Безсмертная Е.Р. Практикум ситуативных заданий как модель обучения студентов-иностранцев языку специальности // Русский язык за рубежом. 2010. № 1. С. 21-32.

20. Кривин Ф. Несерьёзные Архимеды. М.: Издво «Молодая гвардия», 1971. 224 с. 


\title{
DEVELOPMENT OF FOREIGN PHILOLOGICAL STUDENTS' PEDAGOGICAL COMPETENCES BY THE COURSE «PROFESSIOGRAM OF A TEACHER OF RUSSIAN AS A FOREIGN LANGUAGE»
}

(C) 2019

\author{
Filippova Olga Viktorovna, doctor of pedagogical sciences, associate professor, \\ head of Russian as a Foreign Language Department \\ National Research Ogarev Mordovia State University (Saransk, Russian Federation)
}

\begin{abstract}
The paper deals with the role of the discipline «Professiogram of a teacher of Russian as a foreign language» (variable part of Curriculum 45.03.01 Philology, major - «Teaching Russian as a foreign language») for the development of foreign philological students' pedagogical competences. The demand for Russian philological education among foreign students is largely due to the desire to continue teaching. Federal state educational standard of higher education for Curriculum 45.03.01 Philology involves the development of a number of pedagogical competencies that are important for prospective teachers of Russian. To develop necessary competencies and to become a successful specialist it is necessary to get a set of knowledge and skills, culture and experience, which is the professiogram of the teacher of Russian as a foreign language. The paper also deals with the specifics of the academic discipline «Professiogram of a Teacher of Russian as a Foreign Language» and defines the conceptual content, principles and form of practical work. The basis of pedagogical competencies development is a complex of knowledge about requirements for professional activity and personality of the teacher, pedagogical abilities as well as components of pedagogical skills. The specificity of the discipline «Professiogram of a Teacher of Russian as a Foreign Language» is that it develops communicative personality of a prospective teacher. The paper contains examples of practice-oriented tasks.

Keywords: Russian as foreign language; bachelor of Philology; foreign students; pedagogical competence; job analysis of teaching Russian; communicative personality of teacher of Russian as foreign language; principles of teaching communication; rhetoric; case method; rhetorical task.
\end{abstract}

